\title{
Experimental approach and modelling of the mechanical behaviour of graphite fuel elements subjected to compression pulses
}

\author{
P. Forquin ${ }^{1, \mathrm{a}}$ \\ ${ }^{1}$ Laboratory of Physics and Mechanics of Materials, Université Paul Verlaine - Metz, Ile du Saulcy, \\ 57045 Metz Cedex 1, France
}

\section{Abstract}

Among the activities led by the Generation IV International Forum (GIF) relative to the future nuclear systems, the improvement of recycling of fuel elements and their components is a major issue. One of the studied systems by the GIF is the graphite-moderated high-temperature gas cooled reactor (HTGR). The fuel elements are composed of fuel roads half-inch in diameter named compacts. The compacts contain spherical particles made of actinide kernels about $500 \mu \mathrm{m}$ in diameter coated with three layers of carbon and silicon carbide, each about $50 \mu \mathrm{m}$ thick, dispersed in a graphite matrix. Recycling of compacts requires first a separation of triso-particles from the graphite matrix and secondly, the separation of the triso-coating from the kernels. This aim may be achieved by using pulsed currents: the compacts are placed within a cell filled by water and exposed to high voltage between $200-500 \mathrm{kV}$ and discharge currents from 10 to $20 \mathrm{kA}$ during short laps of time (about $2 \mu \mathrm{s}$ ) [1-2]. This repeated treatment leads to a progressive fragmentation of the graphite matrix and a disassembly of the compacts. In order to improve understanding of the fragmentation properties of compacts a series of quasi-static and dynamic experiments have been conducted with similar cylindrical samples containing $10 \%$ (volume fraction) of $\mathrm{SiC}$ particles coated in a graphite matrix.

First, quasi-static compression tests have been performed to identify the mechanical behaviour of the material at low strain-rates (Fig.1). The experiments reveal a complex elasto-visco-plastic behaviour before a brittle failure. The mechanical response is characterised by a low yield stress (about $1 \mathrm{MPa}$ ), a strong strain-hardening in the loading phase and marked hysteresis-loops during unloading-reloading stages. Brittle failure is observed for axial stress about $13 \mathrm{MPa}$. In parallel, a series of flexural tests have been performed with the aim to characterise the quasi-static tensile strength of the particulate-graphite and the corresponding standard deviation. The behaviour being non linear before failure, a numerical simulation has been conducted to build the relation between the applied load and the maximum tensile stress. A statistical approach applied to experimental data allows deducing the mean tensile strength (about $2.5 \mathrm{MPa}$ ) and the scatter of failure stresses (Weibull modulus $m=12$ ).

a e-mail : pascal.forquin@univ-metz.fr

This is an Open Access article distributed under the terms of the Creative Commons Attribution-Noncommercial License 3.0, which permits unrestricted use, distribution, and reproduction in any noncommercial medium, provided the original work is properly cited. 


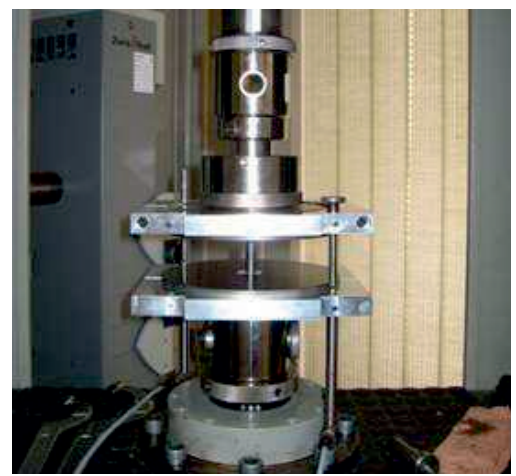

Fig. 1. Compression tests

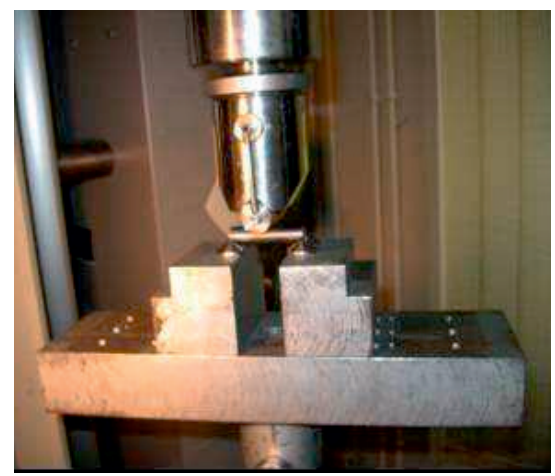

Fig.2. Three point bending tests

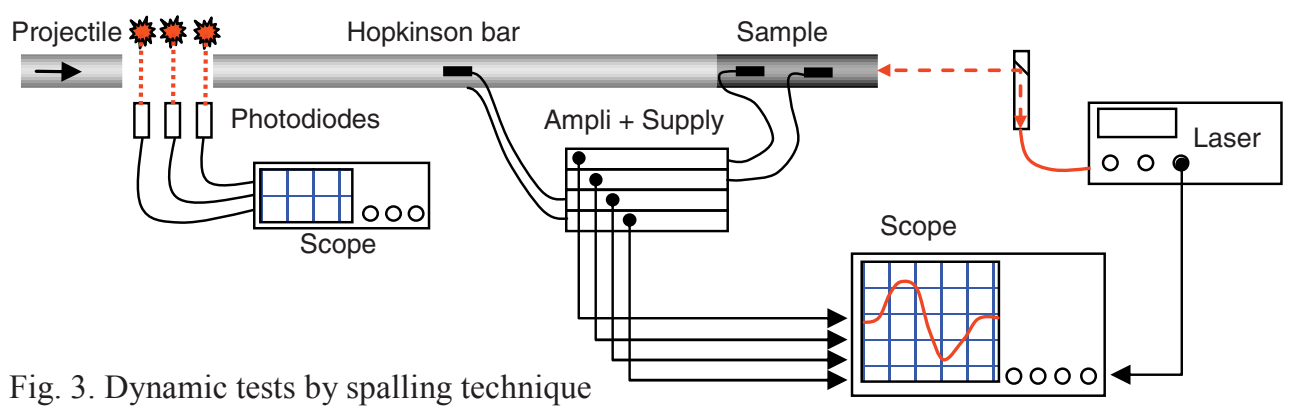

Next, some cylindrical samples have been subjected to dynamic tests by the spalling technique (Fig. 3). This test is quite representative of a dynamic loading by pulsed currents as a short compression pulse generated by impact is transmitted to one side of the specimen. It travels along the cylinder until to reach its free surface where it is reflected as a tensile wave. When the tensile wave exceeds in amplitude the compression pulse, a tensile loading spreads out the sample leading to its possible fragmentation [3-4]. The tests performed in LPMM revealed a huge dissipation of energy in the course of wave propagation due to the strong strain-hardening behaviour of particulate graphite. Consequently, the continuous decrease of the compressive pulse amplitude leads to a limited level of the reflected tensile wave. Thus, these experiments have highlighted the difficulties encountered to fragment these materials despite their very low tensile strength compared to the high pressure levels reached by pulsed currents.

\section{References}

1. M. Masson, S. Grandjean, J. Lacquement, J.-C. Thieblemont, J. Lacombe. Block-type HTGR spent fuels processing: The CEA investigation program. $2^{\text {nd }}$ Int Topical Meeting on High Temperature Reactor Technology. Beijing, China, B05 (2004).

2. M. Masson, S. Grandjean, J. Lacquement, S. Bourg, J.-M. Delauzun, J. Lacombe. Block-type HTGR spent fuel processing: CEA investigation program and initial results. Nuclear Engineering and Design 236 (2006) 516-525.

3. Erzar B., Forquin P. An Experimental Method to Determine the Tensile Strength of Concrete at High Rates of Strain. Experimental Mechanics. DOI: 10.1007/s11340-009-9284-z (2009).

4. Forquin P., Erzar B. Dynamic fragmentation process in concrete under impact and spalling tests. Int. J. of Fracture. DOI: 10.1007/10704-009-9419-3 (2009). 